Montel-Glénisson, Caroline. Champlain au Canada. Les aventures d'un gentilhomme explorateur, récit, illustrations de Michel Glénisson, Paris, Éditions du Nouveau Monde, 2004, 112 p.

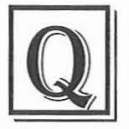

uel charmant ouvrage! Voilà un récit historique véridique qui raconte joliment les débuts de la première colonie française au Canada. L'auteure connaît bien son sujet puisqu'on lui doit aussi une thèse, remarquée par LE MONDE, sur la Nouvelle France. Elle a eu, cette fois, la bonne idée de faire raconter la passionnante aventure de Champlain par des gens simples, Guillaume et Guillaumette. Ils s'adressent à de jeunes enfants. Mais les adultes prendront, comme moi, j'en suis sûr, un bien grand plaisir à les écouter. C'est que Caroline MontelGlénisson possède le grand art de faire parler ses personnages. Avec cette savante, on ne s'ennuie jamais, chose rare en l'occurrence.

En 1613, Champlain cherche des charpentiers et des menuisiers pour construire le fort de Québec. Et voilà notre Guillaume embauché. Il était charpentier de marine à Saint-Malo, sans emploi. Il est courageux et décide de s'installer au Canada pour toujours alors que tant d'autres repartent. "Moi, dit-il, j'ai tout de suite aimé ce pays. Je n'ai jamais eu peur du froid, ni de la maladie, ni des Indiens ». Alors qu'en France la terre n'appartient qu'au seigneur, Champlain en distribue généreusement. Il écoute son monde, partage les idées et les met en pratique.

Nous vivrons un hiver avec Champlain et ses rudes et joyeux compagnons. Puis nous le suivrons dans ses explorations chez les Hu rons, à travers le pays des grands lacs. Guillaume nous raconte les moeurs, coutumes, les chasses et les pêches. Ses lecteurs modernes seront passionnés d'entendre tant de récits colorés. Au passage, la vie ave n tu reuse d'Étienne Brûlé est évoquée. Jeune Français, adopté par les Indiens à dix ans, il apprend plusieurs de leurs langues. Il servira d'interprète et de guide à Champlain. Il vivra bien des aventures avant de se fâcher avec Champlain. Plus tard il le trahira pour se venger du peu de reconnaissance de son maître.

Ce dernier écrit au Roi : "Je pense être sur le point de trouver le passage vers la mer du Sud pour aller à la Chine et aux Indes orientales par le moyen du fleuve Saint-Laurent qui traverse les terres de Nouvelle France ou Canada ». À cette grande illusion sans résultat s'ajoute le désastre de la prise de Québec puis son occupation par les Anglais malgré les ruses de Champlain.

Caroline Montel-Glénisson nous décrit, en peu de pages, un foisonnement de détails sur la vie de ces courageux pionniers de Nouvelle France

\title{
94 LittéRéalité
}


ainsi que sur la vie des tribus indiennes. Dans cet émouvant récit, elle garde toujours le ton de la conversation sans fioritures.

Les aquarelles de Michel Glénisson sont finement dessinées et joliment peintes. Dans les paysages, elles créent un climat d'espace, de mystère, d'ambiance légèrement brumeuse qui convient fort bien à ce récit d'aventure. Je le recommande vivement aux jeunes lecteurs. Mais, encore une fois, il ravira aussi leurs aînés!

Pierre Léon

Université de Toronto

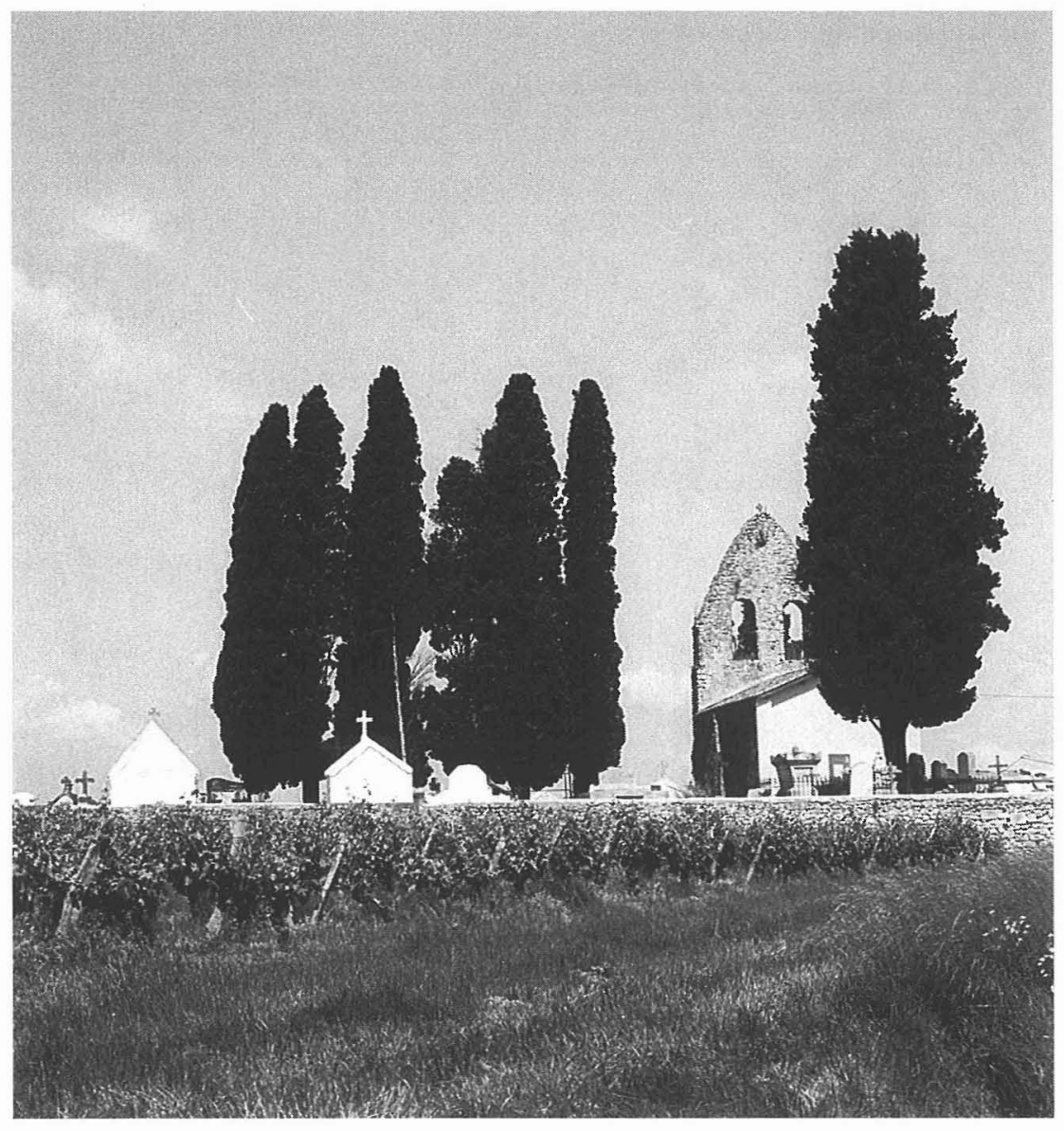

Alan A. Shapiro

L'église de Blasimon, Gironde, 1995. 